Article

\title{
Environmental Control on Transpiration: A Case Study of a Desert Ecosystem in Northwest China
}

\author{
Shiqin $\mathrm{Xu}{ }^{1,2}$ and Zhongbo $\mathrm{Yu}^{1,2, *}$ \\ 1 State Key Laboratory of Hydrology-Water Resources and Hydraulic Engineering, Hohai University, \\ Nanjing 210098, China; shiqinxu1989@hotmail.com \\ 2 College of Hydrology and Water Resources, Hohai University, Nanjing 210098, China \\ * Correspondence: zyu@hhu.edu.cn; Tel.: +86-25-8378-6721
}

Received: 2 March 2020; Accepted: 17 April 2020; Published: 24 April 2020

\begin{abstract}
Arid and semi-arid ecosystems represent a crucial but poorly understood component of the global water cycle. Taking a desert ecosystem as a case study, we measured sap flow in three dominant shrub species and concurrent environmental variables over two mean growing seasons. Commercially available gauges (Flow32 meters) based on the constant power stem heat balance (SHB) method were used. Stem-level sap flow rates were scaled up to stand level to estimate stand transpiration using the species-specific frequency distribution of stem diameter. We found that variations in stand transpiration were closely related to changes in solar radiation $\left(R_{s}\right)$, air temperature $(T)$, and vapor pressure deficit $(V P D)$ at the hourly scale. Three factors together explained $84 \%$ and $77 \%$ variations in hourly stand transpiration in 2014 and 2015, respectively, with $R_{S}$ being the primary driving force. We observed a threshold control of $V P D(\sim 2 \mathrm{kPa})$ on stand transpiration in two-year study periods, suggesting a strong stomatal regulation of transpiration under high evaporative demand conditions. Clockwise hysteresis loops between diurnal transpiration and $T$ and $V P D$ were observed and exhibited seasonal variations. Both the time lags and refill and release of stem water storage from nocturnal sap flow were possible causes for the hysteresis. These findings improve the understanding of environmental control on water flux of the arid and semi-arid ecosystems and have important implications for diurnal hydrology modelling.
\end{abstract}

Keywords: sap flow; water-limited ecosystem; transpiration; hysteresis; nocturnal sap flow

\section{Introduction}

Arid and semi-arid regions covering about $40 \%$ of the terrestrial land surface are highly vulnerable to climate change [1]. Evaluating hydrological response to continuous warming and altered precipitation pattern in these regions largely depends on an accurate estimation of evapotranspiration (ET), especially plant transpiration which can be a large contributor of $E T$, depending on the ecosystem type [2,3]. Sap flow, an indicator of water transport in the plant xylem, provides species-specific estimates of transpiration rate at the whole tree level and can be scaled up to stand level using the appropriate scaling method [4]. During past four decades, sap flow has been widely used to investigate response of transpiration and canopy conductance to environment variables at both daily and sub-daily temporal scales [5], to characterize spatial heterogeneity of water fluxes within stands [6,7], and to quantify the ecosystem water budget $[8,9]$. However, prior studies heavily focused on humid forest ecosystems, with few sap flow field studies in arid and semi-arid ecosystems. What is the primary driving force for transpiration in a water-limited ecosystem at sub-daily scale? To what extent is transpiration controlled by environment variables in these ecosystems? Are there species-specific differences in the responses? These questions need to be addressed to improve our understanding of the water, energy and carbon 
exchange between vegetation and atmosphere, accurate long-term hydrologic modelling, and assess ecosystem adaption in the framework of climate change in arid and semi-arid regions.

Environmental variables that may affect transpiration include solar radiation $\left(R_{S}\right)$, air temperature $(T)$, vapor pressure deficit $(V P D)$, relative humidity $(R H)$, wind speed $(u)$, soil moisture $(\theta)$, soil temperature $\left(T_{S}\right)$, and precipitation $(P)$. Huang et al. [10] reported that sap flow of the Salix psammophila living in a semi-arid environment in northwestern China was positively related to net radiation $\left(R_{n}\right), T$, and $u$, but negatively related to $R H$. They further analyzed water resources of the $S$. psammophila using a correlation analysis and multiple linear regression and found that Salix bushes can use both soil water and groundwater for transpiration. Zheng et al. [11] found that an increase in reference evapotranspiration $\left(E T_{0}\right), P A R, V P D$, and $T$ resulted in an exponential increase in transpiration of the Haloxylon ammodendron (C. A. Mey.) (H. ammodendron), a dominant desert species. Ma et al. [12] reported that sap flow from four typical species of shelter forest in the desert area exhibited a linear relationship with VPD. Shen et al. [13] reported that the sap flow of the Populus gansuensis linearly increased with $R_{s}$, and logarithmically increased with VPD and T. All these studies indicate that the response of transpiration to environmental variables is climateand ecosystem-specific and more research is required to better understand environmental control on transpiration. In addition, diurnal hysteresis between transpiration and environmental variables has been reported in different ecosystems [14-17]. Both transpiration and environmental variables exhibit diurnal changes, reaching peaks at different times and resulting in a hysteresis behavior. Such hysteresis is usually characterized by the looping pattern when measured transpiration time series is plotted against the relevant environmental variables over the course of one day. Plausible explanations include abiotic (such as time lag between radiation and VPD) and biotic factors (such as stem water storage, soil water potential) $[15,18]$. Investigating the hysteric phenomenon and revealing the underlying causes would help to understand the relations and interactions between vegetation and its surrounding environment [18].

The H. ammodendron shrubland is extensively distributed in arid regions of China and plays a crucial role in stabilizing sand dunes and protecting oases from desertification [19]. With the development of irrigated agriculture and rapid population growth in the oasis, over-exploration of water resources has resulted in serious environmental degradations, including a gradually fall of the groundwater table, soil salinization, and desertification [20]. All these environmental problems are threatening the survival of the shrubland. Previous studies have examined the response of the photosynthetic traits and physiological characteristics on enhanced precipitation, nitrogen deposition, and drought stress [21,22], analyzed root distribution characteristics [19], revealed biomass allocation [23], and quantified interactions between canopies and the atmosphere [24]. However, a comprehensive analysis of the relationships between stand transpiration and key environmental variables is still limited.

In the current study, we measured stem sap flow from three dominant species of the H. ammodendron shrubland and related environmental variables over the two main growing seasons. We aimed: (i) to clarify the diurnal course of stand transpiration of the selected shrubland; (ii) to explore relationships between transpiration and key environmental variables; and (iii) to reveal hysteresis of transpiration and explore possible causes.

\section{Material and Methods}

\subsection{Site Description}

We conducted field experiments within an oasis-desert ecotone in the middle of the Heihe River Basin, Northwestern China $\left(100^{\circ} 08^{\prime} 48^{\prime \prime}\right.$ E, 39 $22^{\prime} 07^{\prime \prime} \mathrm{N}$, elevation $\left.1386 \mathrm{~m}\right)$ (Figure 1). The climate in this area is characterized by a typical continental and arid temperate climate with dry and hot summers and cold winters. An analysis of a ten-year meteorological station records (2005-2014) showed that the annual averaged air temperature ranges from $-26{ }^{\circ} \mathrm{C}$ in January to $39^{\circ} \mathrm{C}$ in July, with a mean value of $9{ }^{\circ} \mathrm{C}$; the annual mean precipitation is about $124 \mathrm{~mm}$, with is about $80 \%$ of the annual total fall 
between June and September; the daily averaged sunshine duration is about $8.3 \mathrm{~h}$. The groundwater table in the study area ranged from $4.15 \mathrm{~m}$ to $4.29 \mathrm{~m}$ during the measuring period.

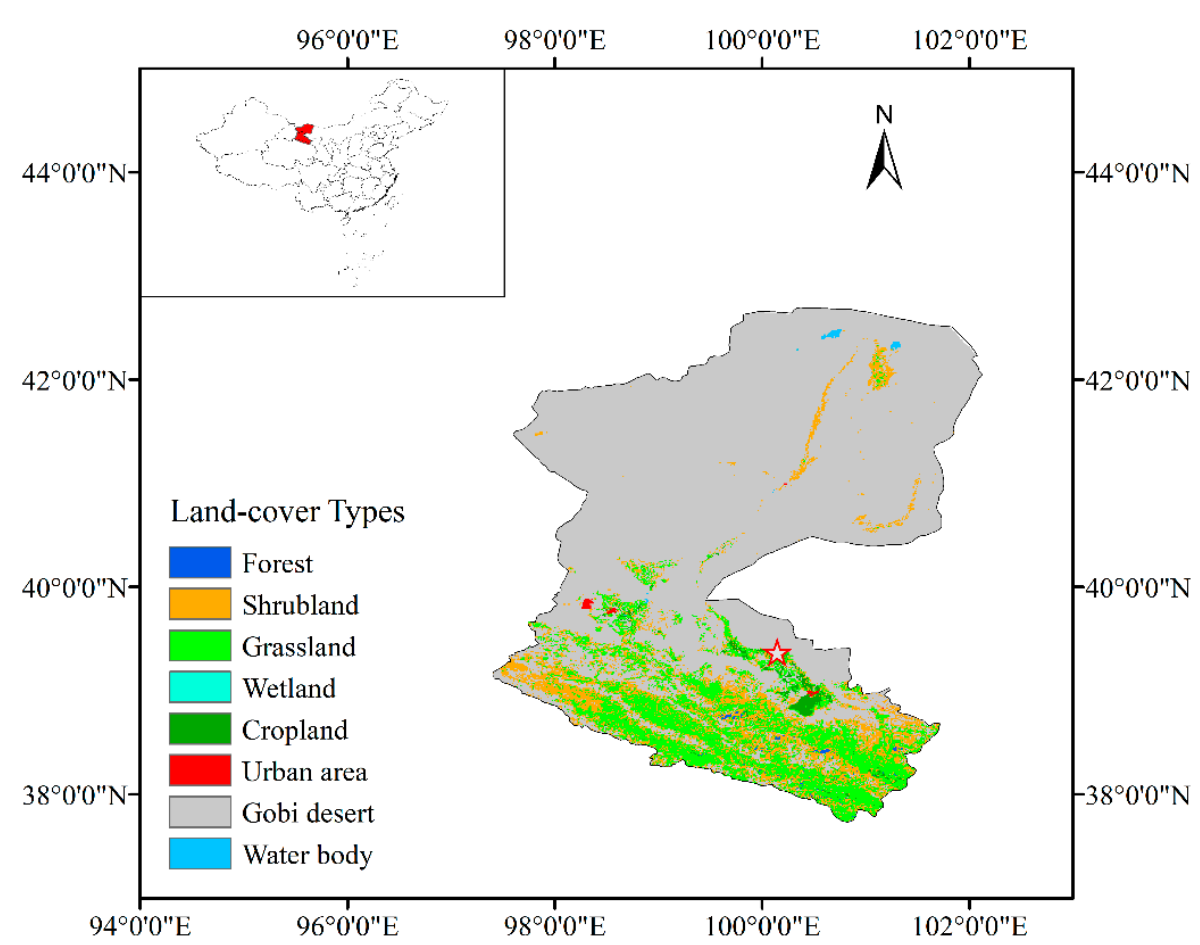

Figure 1. Map of the study area (the land-cover types were obtained from the Moderate Resolution Imaging Spectroradiometer (MODIS) $1 \mathrm{~km}$ IGBP land cover product.

\subsection{Vegetation Measurement}

A representative plot $(50 \times 50 \mathrm{~m})$ of $H$. ammodendron shrubland was selected to conduct vegetation and sap flow measurements. Vegetation within the study plot is characterized by an open shrub canopy consisting of H. ammodendron, Calligonum mongolicum (Turcz.) (C. mongolicum), Nitraria tangutorum (Bobr.) (N. tangutorum), and other shrub and subshrub species. During the intensive experimental period in 2014 (DOY (day of year) 196-222), we measured basal diameter (5 $\mathrm{cm}$ above the ground), height, crown area, leaf area, and stand density. Details on vegetation survey and stand characteristics can be found in our previous study [24].

\subsection{Environmental Measurements}

We constructed a standard automatic weather station within the study plot to measure incoming solar radiation $\left(R_{S}, \mathrm{~W} / \mathrm{m}^{2} ; \mathrm{CNR} 4, \mathrm{Kipp} \&\right.$ Zonen, Delft, Netherlands), photosynthetically active radiation $\left(P A R, \mu \mathrm{mol} / \mathrm{m}^{2} / \mathrm{s}\right.$; LI-190SB, Li-Cor., Lincoln, NE, USA), air temperature $\left(T,{ }^{\circ} \mathrm{C}\right.$; HMP155A, Vaisala, Helsinki, Finland), relative humidity ( $R H, \%$; HMP155A, Vaisala, Helsinki, Finland), wind speed $(u, \mathrm{~m} / \mathrm{s} ; 1405-\mathrm{PK}-052$, Gill Instruments Ltd., Lymington, UK), and precipitation $(P, \mathrm{~mm}$; TE525, Texas Electronics Inc., Dallas, TX, USA). Soil temperature $\left(T_{s},{ }^{\circ} \mathrm{C}\right)$ and soil moisture $\left(\theta, \mathrm{m}^{3} / \mathrm{m}^{3}\right)$ were measured at six depths $(10,20,40,60,80$, and $120 \mathrm{~cm})$ using thermistor probes (109-L, Campbell Scientific Inc., Logan, UT, USA) and time domain reflectometers (CS616, Campbell Scientific Inc., Logan, UT, USA), respectively. All the environmental variables were recorded at 30-min intervals using a data logger (CR1000, Campbell Scientific Inc., Logan, UT, USA). Vapor pressure deficit (VPD, kPa) was calculated using the following equation [25]:

$$
V P D=0.6108 \exp \left(\frac{17.27 T}{T+237.3}\right)\left(1-\frac{R H}{100}\right)
$$




\subsection{Sap Flow Measurements and Estimation of Stand Transpiration}

Sap flow for the three dominant shrub species was measured throughout the growing seasons from DOY 152 to 290 in 2014, and from DOY 141 to 291 in 2015. This ensured that the canopy development of the dominant species at all stages, from leaf emergence to senescence, were sampled. Commercial gauges (Flow32 meters, Dynamax Inc., Houston, TX, USA) based on the constant power stem heat balance (SHB) principle [26] were used to measure sap flow through intact plant stems. We deployed a total of 15 gauges to measure stem sap flow from sample plants of each species. For H. ammodendron, sap flow was measured in nine stems using nine gauges (two gauges of each model for 5 (SGA5), 9 (SGA9), and 13-mm (SGA13) and one gauge of each model for 16 (SGB16), 19 (SGB19), and 25-mm (SGB25)); for N. tangutorum, sap flow was measured in three stems (three 3-mm gauges (model SGA3)); For C. mongolicum, three stems were monitored (one gauge of each model for 5 (SGA5), 9 (SGA9), and 13-mm (SGA13)). We installed gauges on the base of the selected sample stems for each species following the manufacturer's instructions [27]. The data were recorded as 30-min averages by a data logger (CR1000, Cambell Scientific Inc., Logan, UT, USA). We noted that sap flow in the selected stems of N. tangutorum in 2015 was recorded for the period of DOY 143-181 due to gauges' malfunction, resulting in a relative underestimation of stand transpiration in this period.

To scale sap flow rates from individual stems of each species to stand level, the sampling strategy should consider stand structure such as stem size, species distribution, and leaf area [28]. Previous studies demonstrated that leaf area is likely a poor scalar in dry ecosystems, as transpiration per leaf area changed considerably during drought $[29,30]$. We adopted the scaling approach proposed by Allen and Grime [31] in their study of savannah shrubs. They scaled up sap flow rates to whole plot using the frequency distribution of stem diameter and assuming that sap flow rates in each stem were proportional to its cross-sectional area. Their assumption may introduce uncertainties as some studies have observed universal intraspecific variability of sap flow rate among individual trees [28,32]. Future work should conduct individual field measurements including eddy covariance and soil evaporation to comprehensively evaluate the uncertainties. For each species, the stand transpiration $\left(E_{c}, \mathrm{~mm} / \mathrm{h}\right)$ was calculated as follows:

$$
E_{c}=\frac{1}{n} \sum_{i=1}^{n} \frac{0.0001 F_{i}}{A_{i} \rho_{w}} A
$$

where $n$ is the number of gauged stems of each species, $A_{i}$ and $A$ are the basal cross-section area $\left(\mathrm{cm}^{2}\right)$ of stem $i$ and the basal cross-sectional area per ground $\left(\mathrm{cm}^{2} / \mathrm{m}^{2}\right), \rho_{w}$ is the water density $\left(\mathrm{g} \mathrm{cm}^{-3}\right)$, and $F_{i}$ is the sap flow rate in stem $i(\mathrm{~kg} / \mathrm{h})$.

\subsection{Characterizing Hysteresis and Modeling Stand Transpiration}

The time difference between maximum values of diurnal stand transpiration and environmental variables was defined as the time lags [3]. The hysteretic phenomena are associated with clockwise/ anticlockwise loops when measured hourly transpiration rates are plotted against the concurrent environmental variables (such as irradiance, air temperature, and $V P D)[15,18]$.

The Principal Component Analysis (PCA) is a classical method for detecting the underlying structure of the multiple co-varying variables and reducing the dimensionality of data. The derived components are independent and retain most of the information in the original variables. Thus, we used PCA to analyze the environmental conditions that drive transpiration (see Appendix A).

The response of stand transpiration to environmental variables was modeled using the multivariate linear regression as follows:

$$
E_{c}=a \times X_{1}+b \times X_{2}+c \times X_{3}+d
$$

where $X_{1}, X_{2}, X_{3}$, and $X_{4}$ are environmental variables and $a, b, c$ and $d$ are fitted parameters [14]. 
A backward stepwise linear regression analysis was used to determine the influence of environmental variables on stand transpiration. The importance of the predictor can be quantified by comparing the determination coefficient $\left(R^{2}\right)$ of the model fit before and after removing a predictor [3].

\section{Results and Discussion}

\subsection{Stand Characteristics and Environmental Conditions}

H. ammodendron is the dominant species which contributes about $87 \%$ canopy cover; $N$. tangutorum and C. mongolicum are subdominant species comprising $6.8 \%$ and $3.2 \%$ canopy cover, respectively. The frequency distribution of stem diameter for each species in the sample plot indicates that H. ammodendron and C. mongolicum were dominated by small stems $(<2 \mathrm{~cm}$ and $<1 \mathrm{~cm})$ more than $80 \%$ and $73 \%$ of each, respectively. The stems of $N$. tangutorum are much smaller, with stem diameters of $0.2-0.4 \mathrm{~cm}$, contributing $79 \%$ of total stems.

We performed a correlation analysis to examine correlations between environmental variables. The result show that nearly all the environmental variables were correlated to some extent (Table 1). Soil temperature was highly correlated with $T$ and $V P D$ and moderately correlated with $R H$ and $u$. Precipitation was moderately correlated with $R H$. Soil moisture at the surface layer was not correlated with any variable at the 30 -min time scale. The first three PCA components explain $73 \%$ of the variance in the complete environmental data set (Table 2). The first component explains $46 \%$ of the variance in the data and was positively related to $R_{s}, T, V P D$, and $u$ and negatively related to $R H$. The high factor loadings that occurred in the first component occurred on sunny, warm, dry and windy days, representing environmental conditions with high atmospheric evaporative demand (Table 3 ). Therefore, this component was referred to as an atmospheric evaporative demand index. The second component explained the $14 \%$ variance in the data and was positively related to soil temperature and moisture. We refer to this component as a soil index. The third component explains an additional $13 \%$ of the variance and was positively related to precipitation. We refer to this component as a precipitation index. $R_{s}, T$, and $V P D$ were identified as key environmental variables.

Table 1. Correlations among the 30-min averages of environmental variables during the examined period. Coefficients below absolute value of 0.2 are marked with $/ . \theta_{10 \mathrm{~cm}}$ represents soil moisture at surface layer $(0-10 \mathrm{~cm})$.

\begin{tabular}{cccccccc}
\hline Environmental Variables & $\boldsymbol{T}$ & $\boldsymbol{R H}$ & $\boldsymbol{V P D}$ & $\boldsymbol{u}$ & $\boldsymbol{P}$ & $\boldsymbol{T}_{\boldsymbol{s}}$ & $\boldsymbol{\theta}_{\mathbf{1 0 c m}}$ \\
\hline$R_{s}$ & 0.52 & -0.44 & 0.55 & 0.34 & $/$ & $/$ & $/$ \\
$T$ & & -0.59 & 0.88 & 0.40 & $/$ & 0.85 & $/$ \\
$R H$ & & & -0.81 & -0.33 & 0.21 & -0.41 & $/$ \\
$V P D$ & & & & 0.41 & $/$ & 0.71 & $/$ \\
$u$ & & & & $x$ & 0.28 & $/$ \\
$P$ & & & & & $/$ & $/$ \\
$T_{s}$ & & & & & & $/$ \\
\hline
\end{tabular}

Table 2. Eigenvalues and the explained variance by the first three PCA components on the completed environmental data.

\begin{tabular}{cccc}
\hline Axis Number & Eigenvalues & Variance Explained (\%) & Cumulative Variance Explained (\%) \\
\hline 1 & 3.707 & 46 & 46 \\
2 & 1.130 & 14 & 60 \\
3 & 1.022 & 13 & 73 \\
\hline
\end{tabular}


Table 3. Factor loadings on the first three PCA components.

\begin{tabular}{cccc}
\hline \multirow{2}{*}{ Environmental Variables } & \multicolumn{3}{c}{ Component Number } \\
\cline { 2 - 4 } & $\mathbf{1}$ & $\mathbf{2}$ & $\mathbf{3}$ \\
\hline$R_{S}$ & 0.670 & -0.153 & -0.084 \\
$T$ & 0.874 & 0.387 & 0.025 \\
$R H$ & -0.789 & 0.035 & 0.288 \\
$V P D$ & 0.929 & 0.217 & -0.110 \\
$u$ & 0.616 & -0.201 & 0.167 \\
$P$ & -0.066 & -0.019 & 0.956 \\
$T_{S}$ & 0.677 & 0.517 & 0.127 \\
$\theta_{10 \mathrm{~cm}}$ & -0.057 & 0.850 & -0.043 \\
\hline
\end{tabular}

\subsection{Diurnal Courses of Environmental Variables and Transpiration}

Figure 2 shows the diurnal variations of meteorological conditions and transpiration on typical sunny and rainy days. It can be seen that on sunny days, $R_{S}$ increased rapidly in the early morning (between 6:30 and 8:00), peaked in the noon (between 13:00 and 13:30), then declined and dropped near zero at about 20:30. $T$ increased along with $R_{s}$ and reached the maximum of $31.9^{\circ} \mathrm{C}$ between $3: 30$ and 4:00. $V P D$ varied synchronously with $T$, which rapidly increased in the morning and reached the maximum of $3.8 \mathrm{kPa}$ between 3:30 and 4:00. Stand transpiration increased rapidly in the early morning, peaked at about 11:00, gradually declined throughout the afternoon, and reached the minimum after midnight. For individual species, transpiration in $H$. ammodendron resembled the temporal pattern of the stand as this species contributed to the largest proportion of the stand transpiration. The maximum transpiration in N. tangutorum and C. mongolicum occurred later at about 12:00. On rainy days, both stand- and species-specific transpiration considerably decreased due to the decrease in atmospheric evaporative demand represented by lower $R_{S}, T$, and $V P D$. On both sunny and rainy days, hourly stand transpiration was closely related to changes in three environmental variables. We observed a notable midday depression of transpiration during the examined period, which was also reported by other studies in arid and semi-arid habitats $[33,34]$. The depression is mainly caused by stomata closure in response to high vapor-pressure deficit and irradiance in the midday in water-limited ecosystems $[34,35]$. During the measuring period, the maximum stand transpiration ranged from $0.009 \pm 0.003$ to $0.10 \pm 0.02 \mathrm{~mm} / \mathrm{h}$ in 2014 and ranged from $0.006 \pm 0.002$ to $0.12 \pm 0.01 \mathrm{~mm} / \mathrm{h}$ in 2015 .

\subsection{Control of Environment Variables on Stand Transpiration}

Relationships between hourly stand transpiration and three key environmental variables, namely, hourly $R_{s}, T$ and $V P D$, during two-year periods are scatter-plotted in Figure 3. Stand transpiration had a linear correlation with $R_{S}\left(R^{2}=0.81\right.$ in 2014, 0.64 in 2015). Relationships between stand transpiration and $T$ and $V P D$ were well fitted by a two-degree polynomial function $\left(R^{2}=0.41\right.$ in 2014, 0.42 in 2015 for $T ; R^{2}=0.44$ in 2014, 0.40 in 2015 for $V P D$ ). The general patterns between transpiration and three environmental variables are different from water-unlimited ecosystems $[3,36,37]$. For example, Wang et al. [3] examined relationships between hourly transpiration and VPD in the Scots pine (Pinus sylvestris) and found that an increase in VPD resulted in a linear increase in transpiration. We performed stepwise regression to reveal how the environmental variables interactively control stand transpiration. The determination coefficients $\left(R^{2}\right)$ of the regression analysis and specific equation are given in Table 4 and Table A1, respectively. Three variables together explained $84 \%$ of the variance in stand transpiration in 2014, and explained $77 \%$ of the variance in $2015 . R^{2}$ was significantly decreased when $R_{s}$ was not considered, suggesting that stand transpiration was primarily controlled by energy availability. The regression analysis for each month showed similar results. 


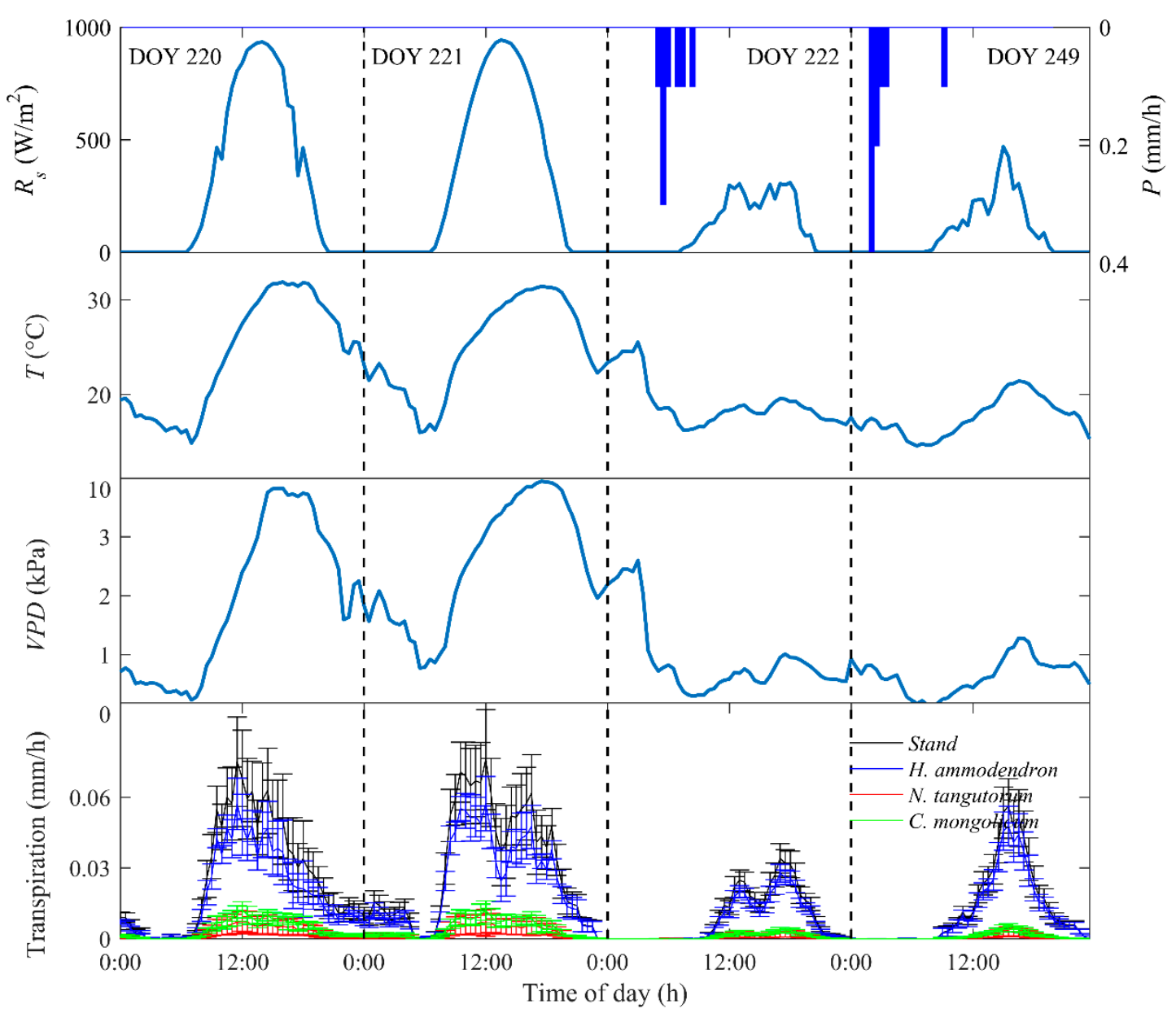

Figure 2. Diurnal courses of half-hourly solar radiation $\left(R_{s}\right)$, air temperature $(T)$, vapor pressure deficit $(V P D)$, precipitation $(P)$, and transpiration for typical sunny days (DOY 220 and 221) and rainy days (DOY 222 and 249) in 2014.

Analyzing the relationship between stand transpiration and $V P D$, we found that stand transpiration increased rapidly with an increase in $V P D$ while it decreased with $V P D>2 \mathrm{kPa}$. The threshold control of $V P D(\sim 2 \mathrm{kPa})$ on stand transpiration in the two-year examined period suggests a stomata regulation of transpiration [38,39]. The result is generally consistent with the studies by Zheng et al. [11], Bai et al. [14], and Tie et al. [40], although with a somewhat different VPD threshold. However, Shen et al. [13] found that the sap flow density of shelter-belt trees in an arid inland river-basin increased logarithmically with VPD. Du et al. [41] reported that the sap flow density of the three forest species growing in the semiarid Loess Plateau region of China saturated at high $V P D$. These results suggested that relations between transpiration and VPD are not only climate specific but also ecosystem specific.

Relations between stand transpiration and soil moisture were weak. The correlation coefficient between stand transpiration and surface soil moisture was 0.05 in 2014 and -0.12 in 2015; the corresponding value for the whole layer soil moisture $(0-120 \mathrm{~cm})$ was 0.11 in 2014 and 0.19 in 2015. This finding is in line with Du et al. [41]. They analyzed the effects of soil moisture on three native and exotic species living in a semi-arid habitat and found that the sap flow density in native species was less sensitive to changes in soil water conditions. However, our result was different from Bovard et al. [5], who observed that hourly sap flow in three forest species declined in dry soil when $V P D$ was higher than $1 \mathrm{kPa}$ and Yin et al. [42] who reported that cumulative sap flow of the Salix matsudana living in semi-arid Hailiutu River catchment was significantly and negatively correlated with soil water content. This is mainly because the H. ammodendron community is dominated by 
drought-resistant shrub species which adopted a more conservative water use strategy for preventing excessive water loss during long-period drought $[19,41]$.
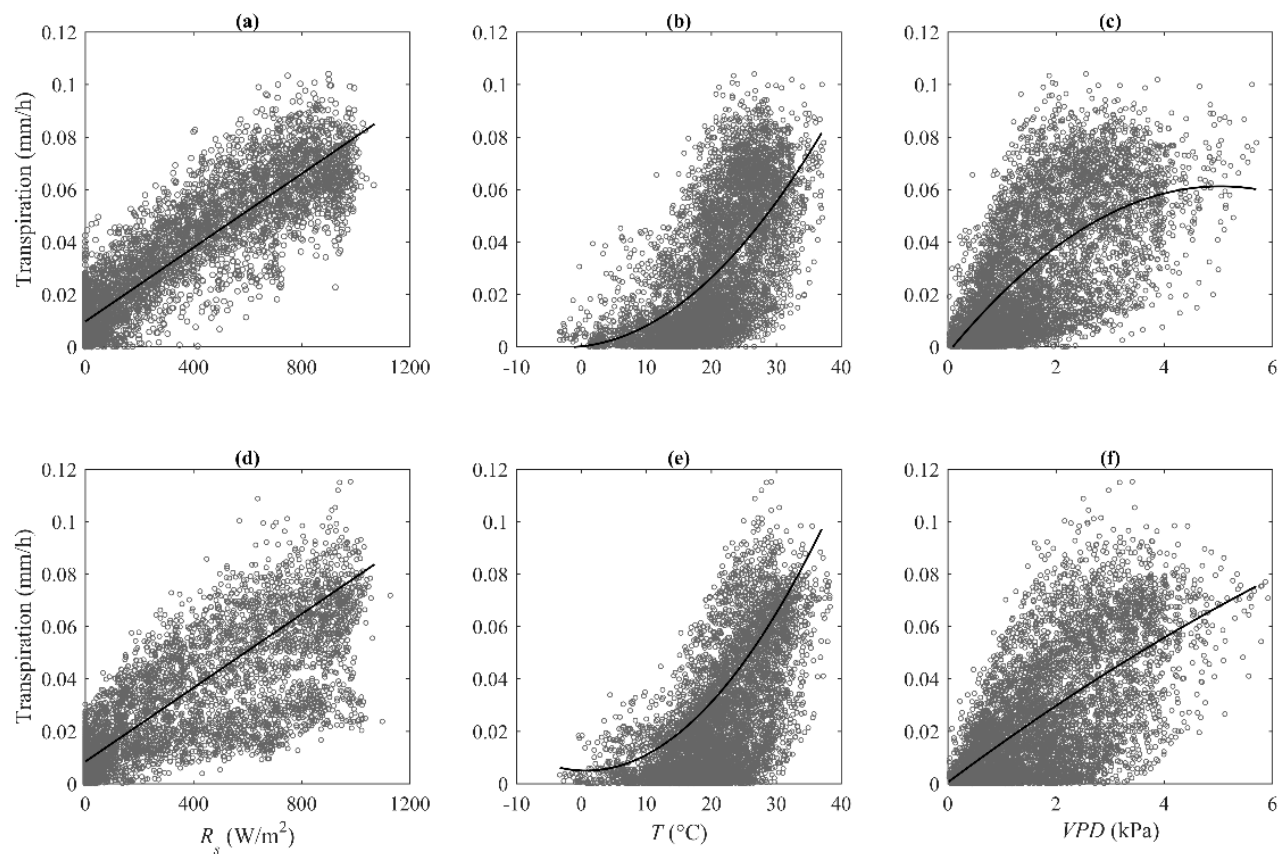

Figure 3. Half hourly stand transpiration against solar radiation $\left(R_{S}\right)$, air temperature $(T)$, and vapor pressure deficit $(V P D)$ during the growing season in $(\mathbf{a}-\mathbf{c}) 2014$ and $(\mathbf{d}-\mathbf{f}) 2015$.

Table 4. Determination coefficient $\left(R^{2}\right)$ of the seasonal bivariate and trivariate stepwise regression models in which stand transpiration is the dependent variable and solar radiation $\left(R_{S}\right)$, air temperature $(T)$, and vapor pressure deficit $(V P D)$ are independent variables.

\begin{tabular}{cccccccc}
\hline Year & Variable & All-time & Jun & July & August & September & October \\
\hline \multirow{4}{*}{2014} & $R_{S}, T, V P D$ & 0.84 & 0.87 & 0.83 & 0.84 & 0.88 & 0.80 \\
& $R_{S}, T$ & 0.84 & 0.87 & 0.83 & 0.84 & 0.88 & 0.79 \\
& $R_{s}, V P D$ & 0.84 & 0.87 & 0.83 & 0.84 & 0.88 & 0.79 \\
& $T, V P D$ & 0.43 & 0.49 & 0.41 & 0.43 & 0.43 & 0.79 \\
& $R_{S}, T, V P D$ & 0.77 & 0.87 & 0.84 & 0.84 & 0.88 & 0.80 \\
\multirow{2}{*}{2015} & $R_{S}, T$ & 0.76 & 0.87 & 0.83 & 0.84 & 0.88 & 0.79 \\
& $R_{s}, V P D$ & 0.76 & 0.87 & 0.83 & 0.84 & 0.88 & 0.79 \\
& $T, V P D$ & 0.43 & 0.49 & 0.41 & 0.43 & 0.43 & 0.40 \\
\hline
\end{tabular}

\subsection{Hysteresis between Stand Transpiration and Environmental Variables}

To further elucidate relationships between transpiration of the H. ammodendron shrubland and related environmental factors, we examined time lags between diurnal maximum transpiration and three key environmental variables during the two-year periods. During the growing season in 2014, the average time of maximum transpiration, $R_{S}, T$, and $V P D$ were 12:00 pm, 13:30 pm, 4:30 pm, and 4:30 pm, respectively. The corresponding times in 2015 were 14:30 pm, 14:00 pm, 4:30 pm, and 4:30 pm, respectively. In 2014, the mean time lags between maximum diurnal transpiration and three variables were $1.5,4.5$, and $4.5 \mathrm{~h}$, respectively, with transpiration occurring before all environmental maxima. Maximum transpiration occurred after maximum $R_{S}$ for half an hour but before the maximum $T$ and VPD for two hours in 2015. We further examined the seasonality of the time lags and found that it varied among months (Figure $4 \mathrm{~b}$ ). For $T$ and $V P D$, time lags decreased from the beginning of the growing season until mid-growing season (July in 2014, August in 2015) and then began to increase towards the end of the growing season. The longest time lags between transpiration and VPD (or T) occurred in October, whereas the shortest time lags were in July. Time lags between 
transpiration and $R_{S}$ had less seasonal regularity compared to time lags between transpiration and $V P D$ and $T$ in the two study years. Wang et al. [3] and Zheng et al. [43] also observed seasonality of time lags in their study. The driving force, however, is still unclear.

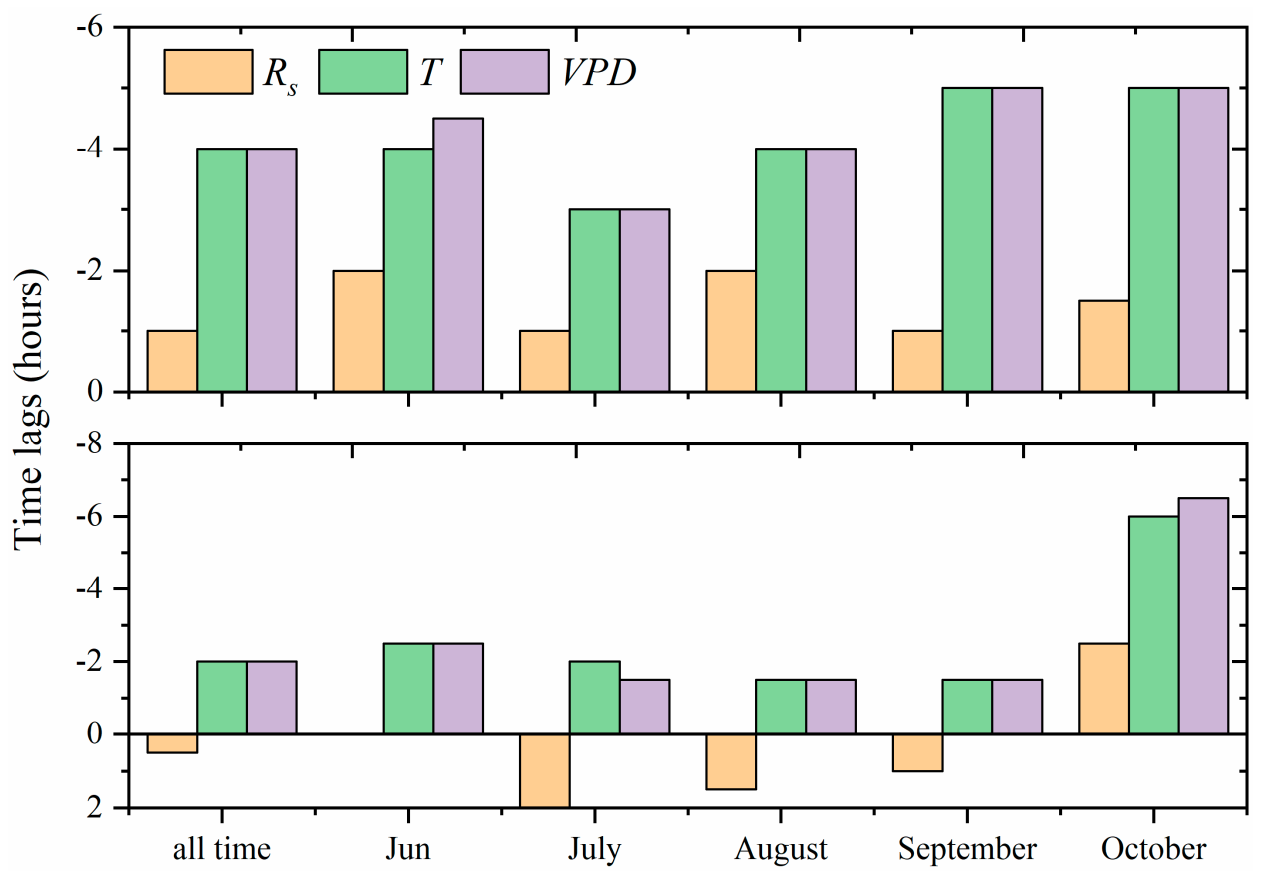

Figure 4. Time lags between maximum stand transpiration and environmental variables including solar radiation $\left(R_{s}\right)$, temperature $(T)$, and vapor pressure deficit $(V P D)$ for different months in (a) 2014 and (b) 2015. Positive values indicate that maximum stand transpiration occurred later than maximum environmental variable.

Plots of 30-min average stand transpiration against $R_{s}, T$, and VPD revealed clockwise hysteresis loops for $T$ and $V P D$ in the two-year examined periods, whereas hysteresis was eliminated or considerably reduced in the $R_{s}$ plots (Figure 5). These patterns are consistent with all three species. The clockwise hysteresis loops between transpiration and $T$ and $V P D$ were in line with previous studies such as Tie et al., O'Grady et al., and Matheny et al. [40,44,45]. However, the result is contrary to Wang et al.'s [3] finding in Scots pine (Pinus sylvestris), where dominant anti-clockwise loops were observed for $T$ and $V P D$. This is mainly because frequent precipitation during their examined period could reduce limitation of water availability and allow transpiration evaporative demand to be relatively constant. Plants tend to close stomatal aperture in the afternoon under high evaporative demand to avoid excessive water loss and thus inhibit transpiration [14,18,36,44,46].

Another possible reason for the hysteresis may be regulation of the water storage in the stems of the shrub, with the release of storage water as sap flow in the early morning prior to variations of the atmosphere conditions $[47,48]$. We quantified nocturnal sap flow (defined as PAR equals to zero [39] ) to daily total water use and found that the contribution of nocturnal sap flow to daily total water use ranged from $0.01 \%$ to $25 \%$ with a mean value of $10 \%$ in 2014 , and ranged from $0.02 \%$ to $34 \%$ with a mean value of $8 \%$ in 2015 (Figure 6). We also observed that nocturnal sap flow was more prominent before midnight, indicating that sap flow before midnight may be used for replenishing the water lost by daytime transpiration (Figure 2). The problem that attributes the nocturnal sap flow to stem water storage is that nighttime sap flow is possibly used for nighttime transpiration [49-51]. We found that $V P D$ and $u$, the factors that usually driving nighttime transpiration [52-54], together explained 44\% and $41 \%$ variations of the nighttime sap flow in 2014 and 2015, respectively (Table 5). In summary, both atmospheric drivers and stem water storage are likely causes of the hysteresis. 

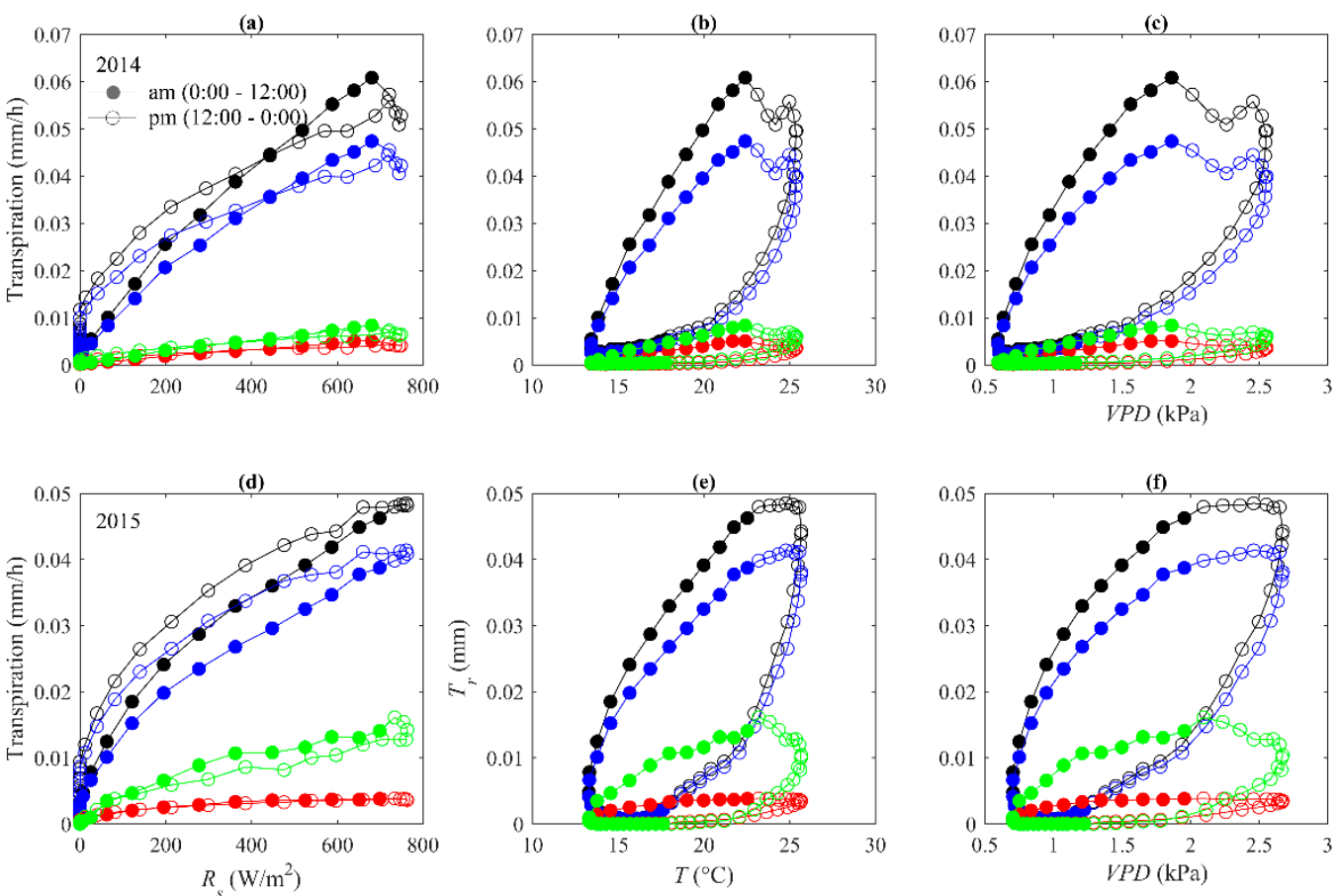

Figure 5. Hysteresis loops between transpiration $\left(T_{r}\right)$ and solar radiation $\left(R_{S}\right)$, air temperature $(T)$, and vapor pressure deficit $(V P D)$ in $(\mathbf{a}-\mathbf{c}) 2014$ and $(\mathbf{d}-\mathbf{f}) 2015$. The black, blue, green, and red cycles represent transpiration in the stand, $H$. ammodendron, $N$. tangutorum, and C. mongolicum, respectively.

Table 5. Multivariate linear equation between nocturnal sap flow and solar radiation, air temperature and vapor pressure deficit.

\begin{tabular}{ccc}
\hline Period & Equation & $\boldsymbol{R}^{\mathbf{2}}$ \\
\hline 2014 & $S F=0.0002+0.0137 V P D+0.0040 u$ & 0.44 \\
2015 & $S F=-0.0012+0.013 V P D+0.0026 u$ & 0.41 \\
\hline
\end{tabular}

(a)

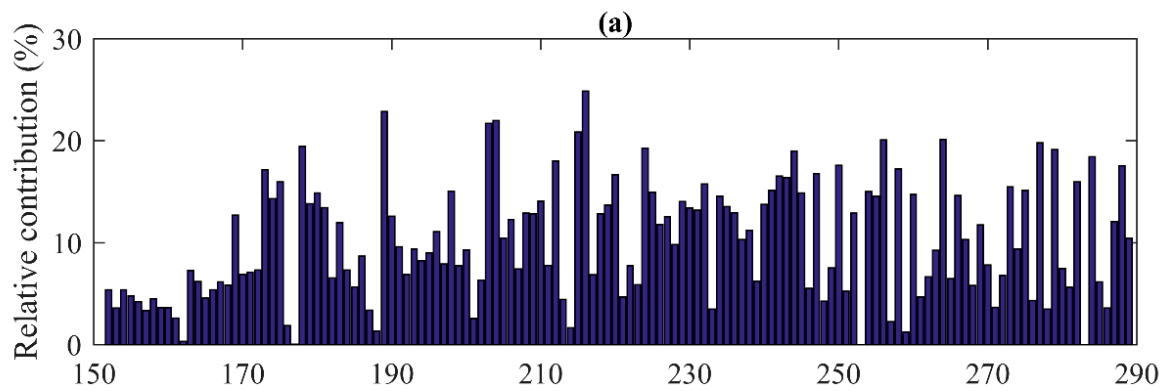

(b)

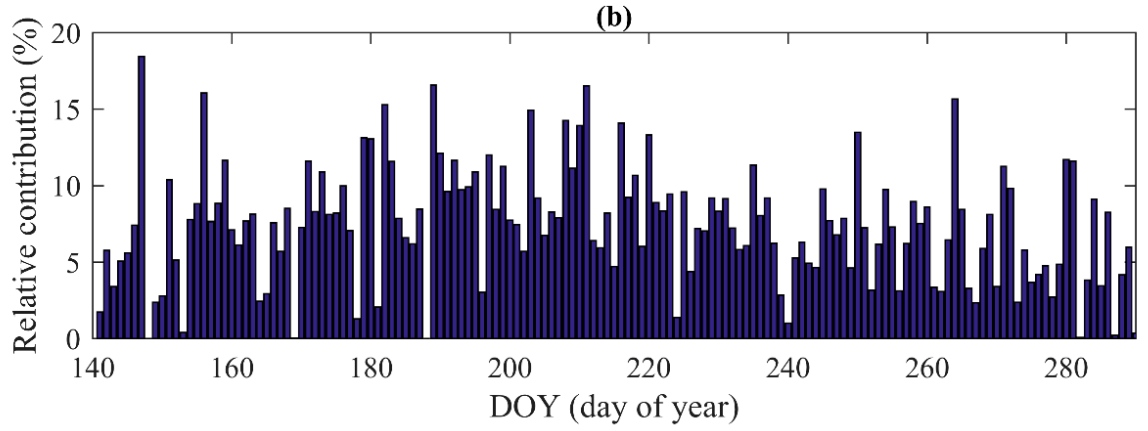

Figure 6. Relative contribution of nocturnal sap flow to daily total water use during the growing season in (a) 2014 and (b) 2015. 


\section{Conclusions}

In the current study, we comprehensively investigated environmental control on transpiration of a desert ecosystem within an oasis-desert ecotone. We measured sap flow from three dominant shrub species and concurrent environmental variables during the growing season in 2014 and 2015. The PCA analysis showed that atmospheric evaporative demand explained the largest proportion of the variance in the environmental data, followed by soil and precipitation indexes. We observed notable midday depression of transpiration during the examined period. At the hourly scale, variations in stand transpiration were closely related to changes in $R_{s}, T$, and $V P D$. Three factors together explained $84 \%$ and $77 \%$ variations in stand transpiration in 2014 and 2015, respectively, with $R_{s}$ being the primary driving force. We observed a threshold control of $V P D(\sim 2 \mathrm{kPa})$ on stand transpiration in the two-year examined periods, which was different from patterns of water-unlimited ecosystem and a part of a water-limited ecosystem. The result suggest a strong stomata regulation of transpiration of the selected desert ecosystem under high evaporative demand conditions. Stand transpiration was not sensitive to changes in soil moisture, as the studied ecosystem was dominated by drought-resistant species which adopt a more conservative water use strategy for preventing excessive water loss during long-period drought. Clockwise hysteresis loops between hourly transpiration and T and VPD were observed during the two growing seasons and exhibited seasonal variations. Both the time lags and stem water storage were possible causes of the hysteresis, while more sophisticated field experiments are required to separate their individual contributions. Our work provides insights into environmental controls on the water flux of arid and semi-arid regions at ecosystem scale and implications for diurnal hydrology modeling, in particular on diurnal transpiration and water stress modeling.

Author Contributions: Conceptualization, Z.Y.; methodology: Z.Y. and S.X.; formal analysis, S.X.; writingoriginal draft preparation, S.X.; writing—review and editing, Z.Y. All authors have read and agreed to the published version of the manuscript.

Funding: This research was funded by the National Key R\&D Program of China (grant number: 2016YFC0402710); the National Natural Science Foundation of China (grant number: 51539003); the Fundamental Research Funds for the Central Universities (grant number: 2018B608X14; 2019B80214); and the Postgraduate Research \& Practice Innovation Program of Jiangsu Province (grant number: KYCX18_0580).

Acknowledgments: We thank three anonymous reviewers for their constructive comments and suggestions which improved the manuscript substantially.

Conflicts of Interest: The authors declare no conflict of interest.

\section{Appendix A}

Computational procedures of the PCA are as following:

(i) Calculating correlation coefficient matrix of the environmental variables.

$$
R=\left[\begin{array}{c}
r_{11} r_{12} \ldots r_{1 p} \\
r_{21} r_{22} \ldots r_{2 p} \\
\ldots \ldots \ldots \\
r_{p 1} r_{p 2} \ldots r_{p p}
\end{array}\right]
$$

where $r_{i j}(i, j=1,2, \ldots, p)$ is the correlation coefficient between variable $x_{i}$ and $x_{j}$. Noting that all the variables should be normalized before calculating the correlation coefficient matrix.

(ii) Calculating eigenvalues and the corresponding eigenvectors.

Solving the equation $|K I-R|=0$ to compute eigenvalues, $K$, and lay them out in order of increasing size: $\kappa_{1} \geq \widehat{K}_{2} \geq \kappa_{3} \ldots \geq \kappa_{p} \geq 0$. Then to solve the eigenvector, $e_{i}(i=1,2, \ldots, p)$, of the corresponding $\kappa_{i}$ with $\sum_{j=1}^{p} e_{i j}^{2}=1$.

(iii) Calculating explained variance of the component $i$ and cumulative variance.

$$
\frac{\Lambda_{i}}{\sum_{k=1}^{p} \Lambda_{k}}(i=1,2, \ldots, p)
$$




$$
\frac{\sum_{k=1}^{i} K_{k}}{\sum_{k=1}^{p} \Lambda_{k}}(i=1,2, \ldots, p)
$$

(iv) Calculating factor loadings of the corresponding component $i$.

$$
\mathrm{l}_{i j}=\mathrm{p}\left(\mathrm{z}_{i}, \mathrm{x}_{j}\right)=\sqrt{\Lambda_{i}} e_{i j}(i, j=1,2, \ldots, p)
$$




\section{Appendix B}

Table A1. Multivariate linear equation between stand transpiration $\left(E_{t}\right)$ and solar radiation $\left(R_{S}\right)$, air temperature $(T)$, and vapor pressure deficit $(V P D)$.

\begin{tabular}{|c|c|c|c|c|c|}
\hline & Time & $R_{s}, T \& V P D$ & $R_{s} \& T$ & $R_{S} \& V P D$ & $T \& V P D$ \\
\hline \multirow{6}{*}{2014} & all-time & $E_{t}=0.001+0.0001 R_{S}+0.0003 T+0.004 V P D$ & $E_{t}=-0.003+0.0001 R_{s}+0.0007 T$ & $E_{t}=-0.003+0.0001 R_{S}+0.004 V P D$ & $E_{t}=-0.004+0.0008 T+0.011 V P D$ \\
\hline & Jun & $E_{t}=-0.002+0.0001 R_{\mathrm{s}}+0.0004 T+0.005 V P D$ & $E_{f}=-0.014+0.0001 R_{\mathrm{s}}+0.0014 T$ & $E_{t}=-0.014+0.0001 R_{s}+0.005 V P D$ & $E_{t}=-0.022+0.002 T+c$ \\
\hline & July & $E_{t}=0.007+0.0001 R_{s}-0.0002 T+0.005 V P D$ & $E_{t}=-0.009+0.0001 R_{s}+0.001 T$ & $E_{t}=-0.009+0.0001 R_{s}+0.005 V P D$ & $E_{t}=-0.033+0.0025 T+0.004 V P D$ \\
\hline & August & $E_{t}=-0.003+0.0001 R_{s}+0.0006 T+0.001 V P D$ & $E_{t}=-0.007+0.0001 R_{S}+0.001 T$ & $E_{t}=-0.007+0.0001 R_{S}+0.001 V P D$ & $E_{t}=-0.041+0.0033 T-0.002 V P D$ \\
\hline & September & $E_{t}=-0.004+0.0001 R_{s}+0.0008 T+0.001 V P D$ & $E_{t}=-0.005+0.0001 R_{s}+0.0009 T$ & $E_{t}=-0.005+0.001 R_{s}+0.001 V P D$ & $E_{t}=-0.022+0.0001 T+0.003 V P D$ \\
\hline & October & $E_{t}=0.002+0.0001 R_{S}+0.0005 T+0.003 V P D$ & $E_{t}=0.002+0.0001 R_{s}+0.0002 T$ & $E_{t}=0.002+0.0001 R_{S}+0.001 V P D$ & $E_{t}=0.001+0.001 T+0.005 V P D$ \\
\hline \multirow{6}{*}{2015} & all-time & $E_{t}=-0.009+0.0001 R_{s}+0.0007 T+0.003 V P D$ & $E_{t}=-0.012+0.0001 R_{s}+0.001 T$ & $E_{t}=-0.012+0.0001 R_{s}+0.003 V P D$ & $E_{t}=-0.009+0.001 T+0.009 \mathrm{VPD}$ \\
\hline & Jun & $E_{t}=-0.002+0.0001 R_{S}+0.0004 T+0.005 V P D$ & $E_{t}=-0.014+0.0001 R_{s}+0.0014 T$ & $E_{t}=-0.014+0.0001 R_{s}+0.005 V P D$ & $E_{t}=-0.022+0.0021 T+0.006 \mathrm{VPD}$ \\
\hline & July & $E_{t}=0.007+0.0001 R_{s}-0.0002 T+0.005 V P D$ & $E_{t}=-0.009+0.0001 R_{s}+0.0009 T$ & $E_{t}=-0.009+0.0001 R_{S}+0.005 V P D$ & $E_{t}=-0.033+0.0024 T+0.004 V P D$ \\
\hline & August & $E_{t}=-0.003+0.0001 R_{S}+0.0006 \mathrm{~T}+0.001 V P D$ & $E_{t}=-0.007+0.0001 R_{S}+0.0009 T$ & $E_{t}=-0.007+0.0001 R_{s}+0.001 V P D$ & $E_{t}=-0.041+0.0033 T-0.002 \mathrm{VPD}$ \\
\hline & September & $E_{t}=-0.004+0.0001 R_{s}+0.0008 T+0.001 V P D$ & $E_{t}=-0.005+0.0001 R_{s}+0.0009 T$ & $E_{t}=-0.004+0.0001 R_{s}+0.001 V P D$ & $E_{t}=-0.022+0.0025 T-0.003 V P D$ \\
\hline & October & $E_{t}=0.002+0.0001 R_{S}+0.0002 T+0.003 V P D$ & $E_{t}=0.002+0.0001 R_{s}+0.0005 T$ & $E_{t}=0.002+0.0001 R_{s}+0.003 V P D$ & $E_{t}=0.001+0.001 T-0.005 V P D$ \\
\hline
\end{tabular}




\section{References}

1. Beuhler, M. Potential impacts of global warming on water resources in southern California. Water Sci. Technol. 2003, 47, 165-168. [CrossRef] [PubMed]

2. Wang, K.; Dickinson, R.E. A review of global terrestrial evapotranspiration: Observation, modeling, climatology, and climatic variability. Rev. Geophys. 2012, 50, RG2005. [CrossRef]

3. Wang, H.; Tetzlaff, D.; Soulsby, C. Hysteretic response of sap flow in Scots pine (Pinus sylvestris) to meteorological forcing in a humid low-energy headwater catchment. Ecohydrology 2019, 12, e2125. [CrossRef]

4. Smith, D.; Allen, S. Measurement of sap flow in plant stems. J. Exp. Bot. 1996, 47, 1833-1844. [CrossRef]

5. Bovard, B.D.; Curtis, P.S.; Vogel, C.S.; Su, H.; Schmid, H.P. Environmental controls on sap flow in a northern hardwood forest. Tree Physiol. 2005, 25, 31-38. [CrossRef]

6. Dalsgaard, L.; Mikkelsen, T.N.; Bastrup-Birk, A. Sap flow for beech (Fagus sylvatica L.) in a natural and a managed forest—effect of spatial heterogeneity. J. Plant Ecol. 2011, 4, 23-35. [CrossRef]

7. Otieno, D.; Li, Y.; Liu, X.; Zhou, G.; Cheng, J.; Ou, Y.; Liu, S.; Chen, X.; Zhang, Q.; Tang, X. Spatial heterogeneity in stand characteristics alters water use patterns of mountain forests. Agric. For. Meteorol. 2017, 236, 78-86. [CrossRef]

8. Wilson, K.B.; Hanson, P.J.; Mulholland, P.J.; Baldocchi, D.D.; Wullschleger, S.D. A comparison of methods for determining forest evapotranspiration and its components: Sap-flow, soil water budget, eddy covariance and catchment water balance. Agric. For. Meteorol. 2001, 106, 153-168. [CrossRef]

9. Zhao, W.; Liu, B.; Chang, X.; Yang, Q.; Yang, Y.; Liu, Z.; Cleverly, J.; Eamus, D. Evapotranspiration partitioning, stomatal conductance, and components of the water balance: A special case of a desert ecosystem in China. J. Hydrol. 2016, 538, 374-386. [CrossRef]

10. Huang, J.; Zhou, Y.; Yin, L.; Wenninger, J.; Zhang, J.; Hou, G.; Zhang, E.; Uhlenbrook, S. Climatic controls on sap flow dynamics and used water sources of Salix psammophilain a semi-arid environment in northwest China. Environ. Earth Sci. 2015, 73, 289-301. [CrossRef]

11. Zheng, C.; Wang, Q. Seasonal and annual variation in transpiration of a dominant desert species, Haloxylon ammodendron, in Central Asia up-scaled from sap flow measurement. Ecohydrology 2014, 8, 948-960. [CrossRef]

12. Ma, J.; Chen, Y.; Li, W.; Huang, X.; Zhu, C.; Ma, X. Sap flow characteristics of four typical species in desert shelter forest and their responses to environmental factors. Environ. Earth Sci. 2012, 67, 151-160. [CrossRef]

13. Shen, Q.; Gao, G.; Fu, B.; Lv, Y. Sap flow and water use sources of shelter-belt trees in an arid inland river basin of Northwest China. Ecohydrology 2015, 8, 1446-1458. [CrossRef]

14. Bai, Y.; Zhu, G.; Su, Y.; Zhang, K.; Han, T.; Ma, J.; Wang, W.; Ma, T.; Feng, L. Hysteresis loops between canopy conductance of grapevines and meteorological variables in an oasis ecosystem. Agric. For. Meteorol. 2015, 214, 319-327. [CrossRef]

15. Zhang, Q.; Stefano, M.; Gabriel, K.; Amilcare, P.; Dawen, Y. The hysteretic evapotranspiration-Vapor pressure deficit relation. J. Geophys. Res. Biogeo. 2014, 119, 125-140. [CrossRef]

16. Hong, L.; Guo, J.; Liu, Z.; Wang, Y.; Ma, J.; Wang, X.; Zhang, Z. Time-Lag effect between sap flow and environmental factors of Larix principis-rupprechtii Mayr. Forests 2019, 10, 971. [CrossRef]

17. Bai, Y.; Li, X.; Liu, S.; Wang, P. Modelling diurnal and seasonal hysteresis phenomena of canopy conductance in an oasis forest ecosystem. Agric. For. Meteorol. 2017, 246, 98-110. [CrossRef]

18. Lin, C.; Gentine, P.; Frankenberg, C.; Zhou, S.; Kennedy, D.; Li, X. Evaluation and mechanism exploration of the diurnal hysteresis of ecosystem fluxes. Agric. For. Meteorol. 2019, 278, 107642. [CrossRef]

19. Xu, S.; Ji, X.; Jin, B.; Zhang, J. Root distribution of three dominant desert shrubs and their water uptake dynamics. J. Plant Ecol. 2017, 10, 780-790. [CrossRef]

20. Ji, X.; Kang, E.; Chen, R.; Zhao, W.; Zhang, Z.; Jin, B. The impact of the development of water resources on environment in arid inland river basins of Hexi region, Northwestern China. Environ. Geol. 2006, 50, 793-801. [CrossRef]

21. Wu, X.; Zheng, X.-J.; Li, Y.; Xu, G. Varying responses of two Haloxylon species to extreme drought and groundwater depth. Environ. Exp. Bot. 2019, 158, 63-72. [CrossRef]

22. Lü, X.; Gao, H.; Zhang, L.; Wang, Y.; Shao, K. Dynamic responses of Haloxylon ammodendron to various degrees of simulated drought stress. Plant Physiol. Biochem. 2019, 139, 121-131. [CrossRef] [PubMed]

23. Xu, G.; Yu, D.; Li, Y. Patterns of biomass allocation in Haloxylon persicum woodlands and their understory herbaceous layer along a groundwater depth gradient. For. Ecol. Manag. 2017, 395, 37-47. [CrossRef] 
24. Xu, S.; Yu, Z.; Zhang, K.; Ji, X.; Yang, C.; Sudicky, E.A. Simulating canopy conductance of the Haloxylon ammodendron shrubland in an arid inland river basin of northwest China. Agric. For. Meteorol. 2018, 249, 22-34. [CrossRef]

25. Allen, R.G.; Pereira, L.S.; Raes, D.; Smith, M. Crop evapotranspiration-Guidelines for computing crop water requirements-FAO Irrigation and drainage paper 56. FAO Rome 1998, 300, D05109.

26. Baker, J.M.; Van Bavel, C.H.M. Measurement of mass flow of water in the stems of herbaceous plants. Plant Cell Environ. 1987, 10, 777-782.

27. Dynamax. Dynagage Sap Flow Sensor User Manual. 2009. Available online: http://dynamax.com/images/ uploads/papers/Dynagage_Manual.pdf (accessed on 6 April 2013).

28. Köstner, B.; Granier, A.; Cermák, J. Sapflow measurements in forest stands: Methods and uncertainties. Ann. For. Sci. 1998, 55, 13-27. [CrossRef]

29. Hatton, T.J.; Wu, H.I. Scaling theory to extrapolate individual tree water use to stand water use. Hydrol. Process. 1995, 9, 527-540. [CrossRef]

30. Hatton, T.J.; Moore, S.J.; Reece, P.H. Estimating stand transpiration in a Eucalyptus populnea woodland with the heat pulse method: Measurement errors and sampling strategies. Tree Physiol. 1995, 15, 219-227. [CrossRef]

31. Allen, S.; Grime, V. Measurements of transpiration from savannah shrubs using sap flow gauges. Agric. For. Meteorol. 1995, 75, 23-41. [CrossRef]

32. Ford, C.R.; McGuire, M.A.; Mitchell, R.J.; Teskey, R.O. Assessing variation in the radial profile of sap flux density in Pinus species and its effect on daily water use. Tree Physiol. 2004, 24, 241-249. [CrossRef] [PubMed]

33. Gartner, K.; Nadezhdina, N.; Englisch, M.; Čermak, J.; Leitgeb, E. Sap flow of birch and Norway spruce during the European heat and drought in summer 2003. For. Ecol. Manag. 2009, 258, 590-599. [CrossRef]

34. Yu, O.; Goudriaan, J.; Wang, T. Modelling diurnal courses of photosynthesis and transpiration of leaves on the basis of stomatal and non-stomatal responses, including photoinhibition. Photosynthetica 2001, 39, 43-51. [CrossRef]

35. Rodrigues, T.R.; Vourlitis, G.L.; Lobo, F.d.A.; Santanna, F.B.; de Arruda, P.H.; Nogueira, J.d.S. Modeling canopy conductance under contrasting seasonal conditions for a tropical savanna ecosystem of south central Mato Grosso, Brazil. Agric. For. Meteorol. 2016, 218, 218-229. [CrossRef]

36. Wullschleger, S.D.; Wilson, K.B.; Hanson, P.J. Environmental control of whole-plant transpiration, canopy conductance and estimates of the decoupling coefficient for large red maple trees. Agric. For. Meteorol. 2000, 104, 157-168. [CrossRef]

37. Clausnitzer, F.; Köstner, B.; Schwärzel, K.; Bernhofer, C. Relationships between canopy transpiration, atmospheric conditions and soil water availability-Analyses of long-term sap-flow measurements in an old Norway spruce forest at the Ore Mountains/Germany. Agric. For. Meteorol. 2011, 151, 1023-1034. [CrossRef]

38. Meinzer, F.; Goldstein, G.; Holbrook, N.; Jackson, P.; Cavelier, J. Stomatal and environmental control of transpiration in a lowland tropical forest tree. Plant Cell Environ. 1993, 16, 429-436. [CrossRef]

39. Motzer, T.; Munz, N.; Küppers, M.; Schmitt, D.; Anhuf, D. Stomatal conductance, transpiration and sap flow of tropical montane rain forest trees in the southern Ecuadorian Andes. Tree Physiol. 2005, 25, 1283-1293. [CrossRef]

40. Tie, Q.; Hu, H.; Tian, F.; Guan, H.; Lin, H. Environmental and physiological controls on sap flow in a subhumid mountainous catchment in North China. Agric. For. Meteorol. 2017, 240, 46-57. [CrossRef]

41. Du, S.; Wang, Y.; Kume, T.; Zhang, J.; Otsuki, K.; Yamanaka, N.; Liu, G. Sapflow characteristics and climatic responses in three forest species in the semiarid Loess Plateau region of China. Agric. For. Meteorol. 2011, 151, 1-10. [CrossRef]

42. Yin, L.; Zhou, Y.; Huang, J.; Wenninger, J.; Uhlenbrook, S. Dynamics of willow tree (Salix matsudana) water use and its response to environmental factors in the semi-arid Hailiutu River catchment, Northwest China. Environ. Earth Sci. 2014, 71, 4997-5006. [CrossRef]

43. Zheng, H.; Wang, Q.; Zhu, X.; Li, Y.; Yu, G. Hysteresis responses of evapotranspiration to meteorological factors at a diel timescale: Patterns and causes. PLoS ONE 2014, 9, e98857. [CrossRef] [PubMed]

44. O'Grady, A.P.; Worledge, D.; Battaglia, M. Constraints on transpiration of Eucalyptus globulus in southern Tasmania, Australia. Agric. For. Meteorol. 2008, 148, 453-465. [CrossRef] 
45. Matheny, A.M.; Bohrer, G.; Vogel, C.S.; Morin, T.H.; He, L.; Frasson, R.P.d.M.; Mirfenderesgi, G.; Schäfer, K.V.; Gough, C.M.; Ivanov, V.Y. Species-specific transpiration responses to intermediate disturbance in a northern hardwood forest. J. Geophys. Res. Biogeo. 2014, 119, 2292-2311. [CrossRef]

46. Chen, L.; Zhang, Z.; Li, Z.; Tang, J.; Caldwell, P.; Zhang, W. Biophysical control of whole tree transpiration under an urban environment in Northern China. J. Hydrol. 2011, 402, 388-400. [CrossRef]

47. Meinzer, F.C.; James, S.A.; Goldstein, G. Dynamics of transpiration, sap flow and use of stored water in tropical forest canopy trees. Tree Physiol. 2004, 24, 901-909. [CrossRef] [PubMed]

48. Goldstein, G.; Andrade, J.; Meinzer, F.; Holbrook, N.; Cavelier, J.; Jackson, P.; Celis, A. Stem water storage and diurnal patterns of water use in tropical forest canopy trees. Plant Cell Environ. 1998, 21, 397-406. [CrossRef]

49. Dawson, T.E.; Burgess, S.S.; Tu, K.P.; Oliveira, R.S.; Santiago, L.S.; Fisher, J.B.; Simonin, K.A.; Ambrose, A.R. Nighttime transpiration in woody plants from contrasting ecosystems. Tree Physiol. 2007, 27, 561-575. [CrossRef]

50. Rosado, B.H.; Oliveira, R.S.; Joly, C.A.; Aidar, M.P.; Burgess, S.S. Diversity in nighttime transpiration behavior of woody species of the Atlantic Rain Forest, Brazil. Agric. For. Meteorol. 2012, 158, 13-20. [CrossRef]

51. Snyder, K.; Richards, J.; Donovan, L. Night-time conductance in C3 and C4 species: Do plants lose water at night? J. Exp. Bot. 2003, 54, 861-865. [CrossRef]

52. Daley, M.J.; Phillips, N.G. Interspecific variation in nighttime transpiration and stomatal conductance in a mixed New England deciduous forest. Tree Physiol. 2006, 26, 411-419. [CrossRef] [PubMed]

53. Phillips, N.; Ryan, M.; Bond, B.; McDowell, N.; Hinckley, T.; Čermák, J. Reliance on stored water increases with tree size in three species in the Pacific Northwest. Tree Physiol. 2003, 23, 237-245. [CrossRef] [PubMed]

54. Phillips, N.G.; Lewis, J.D.; Logan, B.A.; Tissue, D.T. Inter-and intra-specific variation in nocturnal water transport in Eucalyptus. Tree Physiol. 2010, 30, 586-596. [CrossRef] [PubMed]

(C) 2020 by the authors. Licensee MDPI, Basel, Switzerland. This article is an open access article distributed under the terms and conditions of the Creative Commons Attribution (CC BY) license (http://creativecommons.org/licenses/by/4.0/). 